\title{
Quantification of Maximal Force Produced in Standard and Contra- Standard Sculling in Synchronized Swimming. A Pilot Study
}

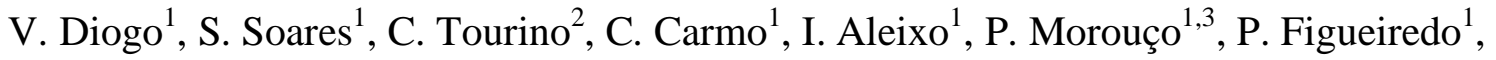 \\ J.P. Vilas-Boas ${ }^{1}$ and R.J. Fernandes ${ }^{1, *}$ \\ ${ }^{I}$ Centre of Research, Education, Innovation and Intervention in Sport, Faculty of Sport, University of Porto, Portugal \\ ${ }^{2}$ Faculty of Science of Education and of Sport, University of Vigo, Spain \\ ${ }^{3}$ Center of Research for Human Movement Sciences, Polytechnic Institute of Leiria, Portugal
}

\begin{abstract}
Studies carried out in synchronized swimming are very scarce, namely those which include biomechanical analysis of the sculling technique. The purpose of this study was to measure the maximal force produced in standard and contra-standard sculling, using a 30s maximal tethered synchronized swimming test. One former female synchronized swimmer and one former female swimmer performed a 2x30s maximum intensity tethered synchronized swimming test, in standard and contra-standard sculling conditions, respectively. Parameters studied were maximal, mean and minimum force, the time when maximal and minimum force occurred, and fatigue index. Results showed that the higher values of maximal and mean force were found in standard sculling, both for the synchronized swimmer and the swimmer. The swimmer attained higher values of absolute and relative maximal force in the standard sculling, but lower values in the contra-standard technique, when compared to the synchronized swimmer. Fatigue Index results evidence that the maximal force declined during the $30 \mathrm{~s}$ in both participants and in both sculling conditions. This parameter was higher for the contra-standard sculling performed by the swimmer, and for the standard sculling for the synchronized swimmer. In conclusion, there were differences in force production in standard and contra-standard sculling between a swimmer and a synchronized swimming. Those differences could probably be explained by differences in skill competence.
\end{abstract}

Keywords: Biomechanics, sculling, synchronized swimming, tethered swimming.

\section{INTRODUCTION}

Synchronized swimming is a complex and physically demanding sport, in which the strength demands and the velocity of movements is combined with high flexibility requirements $[1,2]$. In this sport, sculling is an often used technique [1], consisting in underwater arm stroke patterns, with the objective of producing a hydrodynamic force that allows support, balance and propulsion to the swimmer's body $[1,3]$.

Although the importance of sculling is undeniable in synchronized swimming, very few studies are known, and none seems to have quantified the maximal force (Fmax) produced by the swimmer. Knowing that there is a high relationship between force and performance in swimming [4], and that strength training (with emphasis on neural adaptations) explains, in part, the specific positive changes in velocity and aerobic performance due to a better economy of movement $[5,6]$, the purpose of this study was to measure the Fmax produced in standard and contra-standard sculling, using a 30 s maximal tethered synchronized swimming test.

*Address correspondence to this author at the Faculty of Sport, University of Porto, Portugal; Tel: +351 225074763; E-mail: Ricfer@ fade.up.pt

\section{METHODS}

One former female synchronized swimmer (32 years old, height $1.65 \mathrm{~m}$, body mass $49.7 \mathrm{~kg}$ and 5 years of practice) and one former female swimmer (26 years old; height, 1.67 $\mathrm{m}$; body mass, $58 \mathrm{~kg}$ and 12 years of practice) volunteered to participate in the present study.

A 30s tethered swimming protocol was used in order to determine individual force to time - $\mathrm{F}(\mathrm{t})$ - curves, in two conditions: (i) standard sculling (movement towards the head, with the body placed in supine position, the arms in the lateral of the trunk, the wrist in dorsal flexion and the hand oriented toward the feet) and (ii) contra-standard sculling (movement towards the feet with the body in supine position, the arms in the lateral of the trunk, the wrist in palmar flexion and the hand oriented towards the head). After a familiarization with the equipment and a standardized warmup, each subject performed a 30s maximum intensity tethered synchronized swimming test. Individual $F(t)$ curves were obtained with the subjects attached by a non-elastic cable to a strained-gauge system (Globus, Italy). The beginning and the end of the test were established through an acoustical signal produced by the researcher. Tests were conducted in an indoor, heated $\left(27.5^{\circ} \mathrm{C}\right)$ and $2 \mathrm{~m}$ deep swimming-pool.

Microsoft Office Excel 2003 was used to compute the relative maximal force (relative Fmax $=$ Force $/$ Weight), the 
average of maximal force (FmaxAvg = average of the five highest values during the test) and the fatigue index (FI (\%) $=([$ Fmax - Fmin $) /$ Fmax $] \times 100)$.

\section{RESULTS}

Values of Fmax and minimal force (Fmin), as well as the time when these values occurred, are presented in Table $\mathbf{1}$ in both standard and contra-standard sculling for the two subjects studied. Additionally, the relative Fmax, FmaxAvg and the FI can also be observed.

It is possible to observe that for the synchronized swimmer and the swimmer the higher values of Fmax and FmaxAvg were both found in standard sculling. Comparing the subjects, it is possible to observe that the swimmer attained higher values of Fmax and relative Fmax in the standard sculling, but lower values in the contra-standard technique, when compared to the synchronized swimmer. The values of FI evidence that the Fmax, despite all the fluctuations (cf. an example in Fig. (1)), declined during the 30s in both participants and in both sculling conditions. Interestingly, this parameter was higher for the contra-standard sculling performed by the swimmer, and for the standard sculling for the synchronized swimmer.

\section{DISCUSSION}

Nonetheless the fact that the present study is conducted only with two subjects, and that both are former athletes, it is the first time that Fmax (and even FI) produced in standard and contra-standard sculling was assessed.
Earlier studies conducted in swimming showed that the relationship between the forces exerted during the tethered swimming test vary according to age, maturation state and competitive level $[7,8]$. Indeed, the difference in age may be one of the explanations for the differences in the levels of force attained by our subjects. However, it seems that this is not the main reason for the obtained results, because swimmer (which is younger) only reaches higher levels of force (absolute and relative) in standard sculling. Thus, the higher resemblance between swimming and standard sculling can be the main explanation. These facts can be evidenced using video images during the tethered swimming test, which will enable a detailed analysis of the sculling movement. This procedure will be carried out in future studies.

An attempt to compare the presented results to the specialized literature was not fruitful because reference values of force in synchronized swimming were not found. Swimming studies show that swimmers reach significantly higher levels of force compared to those observed in the present study, which may occurred due to: (i) wider amplitudes of the front crawl underwater phases; (ii) higher propulsive continuity in front crawl due the existence of three underwater phases in opposition to sculling that only have two phases [9]; and (iii) the use of both upper and lower limbs.

Complementarily, both subjects are former swimmers, which can explain the low values of force and the high values of FI comparing to trained swimmers (cf. [10]). Morouço et al. [10] mentioned that swimmers who reach high peaks of force are not able to maintain their values for so long, which

Table 1. Values of Maximal (Absolute and Relative) and Minimal Force (Fmax, Relative FMax and Fmin, Respectively), the Time when these Values Occurred, the Average of Maximal Force (FmaxAvg) and Fatigue Index (FI) in Standard and Contra-Standard Sculling in both Participants

\begin{tabular}{|l|c|c|c|c|}
\hline & $\begin{array}{c}\text { Synchronized Swimmer } \\
\text { (Standard) }\end{array}$ & $\begin{array}{c}\text { Synchronized Swimmer } \\
\text { (Contra-Standard) }\end{array}$ & $\begin{array}{c}\text { Swimmer } \\
\text { (Standard) }\end{array}$ & $\begin{array}{c}\text { Swimmer } \\
\text { (Contra-Standard) }\end{array}$ \\
\hline \hline Fmax (N) & 31.47 & 26.83 & 41.85 & 19.31 \\
\hline Relative Fmax (N/Kg) & 0.63 & 0.54 & 0.72 & 0.33 \\
\hline FmaxTime (s) & 2.50 & 2.80 & 3.70 & 3.25 \\
\hline Fmin (N) & 0.36 & 2.86 & 3.93 & 0.36 \\
\hline FminTime (s) & 10.45 & 11.05 & 26.65 & 22.00 \\
\hline FmaxAvg (N) & 29.26 & 25.89 & 35.05 & 18.24 \\
\hline FI (\%) & 78.40 & 18.27 & 61.34 & 71.50 \\
\hline
\end{tabular}

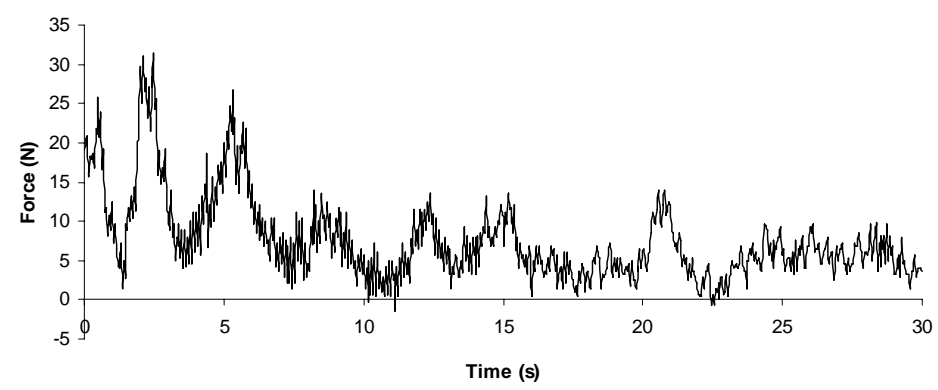

Fig. (1). Example of an individual $\mathrm{F}(\mathrm{t})$ curve in standard sculling of the synchronized swimmer. 
is not supported by these data. The swimmer reached a higher peak of force in standard sculling and also reached minimal values of force later than synchronized swimmer. Moreover, the lowest fatigue index that the swimmer attained also was in standard sculling movement. This can be explained by reasons already mentioned above: the swimmer is younger, quit training more recently, practiced for more years, and possibly has a better physical general condition.

Comparing standard with contra-standard sculling, the synchronized swimmer and the swimmer produced more intense forces in standard sculling. However, the difference between the Fmax of both sculling is greater in the swimmer, wherever the Fmax of standard sculling is much higher than the contra-standard sculling. These results were expected since synchronized swimmers are much more used to perform contra-standard sculling motions than the swimmer.

\section{REFERENCES}

[1] Chu D. Athletic training issues in synchronized swimming. Clin Sports Med 1999; 18 (2): 437-45.

[2] Mountjoy M. The basics of synchronized swimming and its injuries. Clin Sports Med 1999; 18 (2): 321-36.

[3] Martins M, Oliveira C, Silva A, et al. Natação Sincronizada: descrição técnica, modelo de ensino e regulamento desportivo. Vila Real: UTAD 2006.
[4] Risch O, Castro F. Desempenho em natação e pico de força em tethered swimming. In: Anais do XII Congresso Brasileiro de Biomecânica; 2007: Águas de São Pedro, São Paulo; 2007; pp. 441-6.

[5] Hoff J, Gran A, Helgerud J. Maximal strength training improves aerobic endurance performance. Scand J Med Sci Sports 2002; 12: 288-95.

[6] Osteras H, Helgerud J, Hoff J. Maximal strength-training effects on force-velocity and force-power relationship explains increases in aerobic performance in humans. Eur J Appl Physiol 2002; 88: 25563.

[7] Vorontsov A, Dyrco V, Binevsky D, Solomatin V, Sidorov N Patterns of growth for some characteristics of physical development, functional and motor abilities in boy-swimmers 11-8 years. In: Keskinen K, Komi P, Hollander AP, Eds. Biomechanics and medicine in swimming VIII; 1998: Jyväskulä, Finland: Gummerus Printing 1999; pp. 327-35.

[8] Sidney M, Pelayo P, Robert A. Tethered forces in crawl stroke and their relationship to anthropometrics characteristics and sprint swimming performance. J Hum Mov Stud 1996; 31: 1-12.

[9] Rackham GW. An analysis of arm propulsion in swimming. In: Lewillie L, Clarys JP, Eds. $2^{\text {nd }}$ International Symposium on Biomechanics in Swimming; 1974: Brussels, Belgium: University Park Press. 1974; pp.174-9.

[10] Morouço P, Soares S, Vilas-Boas JP, Fernandes R. Association between 30sec maximal tethered swimming and swimming performance in front crawl. In: North American Congress on Biomechanics. Available from: http://www.nacob2008.org 